\title{
Temperature dependent mechanical properties of zirconium processed by high-pressure torsion at 300 and $77 \mathrm{~K}$
}

\author{
A. V. Podolskiy ${ }^{1,2}$, E. D. Tabachnikova ${ }^{1}$, B. Bonarski ${ }^{2}$, D. Setman ${ }^{2}$, C. Mangler ${ }^{2}$, E. Schafler $^{2}$, \\ M. J. Zehetbauer ${ }^{2 *}$
${ }^{1}$ B. Verkin Institute for Low Temperature Physics 83 Engineering, Science Ave. 47, Kharkov, 61103, Ukraine
${ }^{2}$ Physics of Nanostructured Materials, Faculty of Physics, University of Vienna, Boltzmanngasse 5, A-1090 Wien, Austria

Received 6 March 2015, received in revised form 8 July 2015, accepted 9 July 2015

\begin{abstract}
Several structural states of nanostructured zirconium (average grain size of $80-200 \mathrm{~nm}$ ) were achieved by high pressure torsion (HPT) at temperatures 300 and $77 \mathrm{~K}$, at pressures of 2 and $4 \mathrm{GPa}$ with and without subsequent annealing. Mechanical properties of the nanostructured $\mathrm{Zr}$ were investigated by uniaxial compression at temperatures 300, 77 and $4.2 \mathrm{~K}$. Comparison of the strength characteristics, plasticity and strain hardening of the nanostructured and coarse-grained Zr has been carried out. The influences of static recovery occurring after HPT at $77 \mathrm{~K}$, and of twinning, on plasticity and strength of nanostructured $\mathrm{Zr}$ have been discussed.
\end{abstract}

Key words: SDP induced nanostructure, zirconium, low-temperature deformation, texture, twinning

\section{Introduction}

Zirconium is a representative of hexagonal close packed (hcp) metals and a perspective material for constructional applications. The mechanisms of its plastic deformation were intensively studied in the coarse-grained state $[1-6]$. It was found that dislocation slip and twinning are the main deformation mechanisms at ambient and lower deformation temperatures, their relative activity depending on factors like temperature, impurity concentration, and initial texture. Activity and mutual interaction of these mechanisms determine the mechanical properties observed $[1-6]$.

In recent years, the microstructure and properties of ultrafine grained and nanostructured materials, achieved by various methods of severe plastic deformation, have been intensely studied [7-9]. High-pressure torsion (HPT) at ambient temperature was used to produce nanostructured states in $\mathrm{Zr}$ with emphasis on HPT-induced phase transition from $\alpha$ phase being stable under normal conditions to a mixture of $\omega$ and $\beta$ phase $[10,11]$. The influence of HPT induced $\alpha-\omega$ phase transformation on mechanical properties of $\mathrm{Zr}$ at room temperature was also studied in detail [12].

In the present work the main attention is paid to the nature of deformation mechanisms and the factors, which influence the plasticity and strength of HPT nanostructured $\alpha$-Zr, such as impurity content, distribution of lattice defects inside the grains, the structure of grain boundaries, the presence of twin boundaries, etc. Several nanostructured states of $\mathrm{Zr}$ have been achieved by HPT at various pressures and temperatures, in particular at cryogenic temperature of $77 \mathrm{~K}$. A part of samples was annealed at moderate temperatures in order to achieve low energy grain boundaries with still small grain size. The aim of the present paper was (i) to study and compare the microstructures of these HPT-nanostructured states, and (ii) to investigate the mechanical properties of the different nanostructured states in the temperature range of 4.2 $300 \mathrm{~K}$. The final goal was to reveal the specific influence of different microstructural elements on strength and plasticity of nanostructured $\mathrm{Zr}$ in a wide range of temperatures.

*Corresponding author: michael.zehetbauer@univie.ac.at 


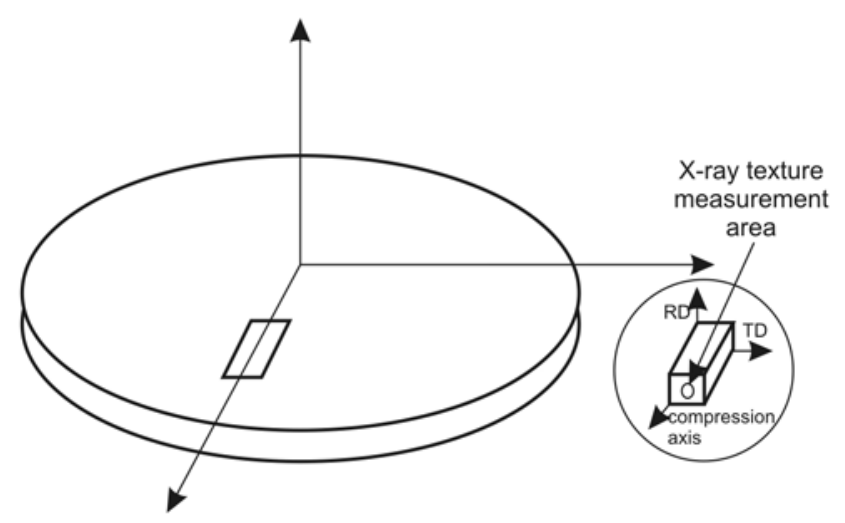

Fig. 1. Experimental setup for cutting the compression samples from HPT discs or initial extruded discs. The sketch to the right shows the compression sample with the direction of compression axis and reference system of the texture pole figures.

\section{Experimental materials and procedures}

Polycrystalline zirconium in rods with an average grain size of $10 \mu \mathrm{m}$, and a total impurity content of about 0.2 wt.\%, including: $0.025 \% \mathrm{C}, 0.25 \% \mathrm{Hf}$, $0.02 \% \mathrm{Fe}, 0.02 \% \mathrm{Cr}, 0.01 \% \mathrm{~N}, 0.1 \% \mathrm{O}, 0.001 \%$ $\mathrm{H}$, was used as initial material.

Severe plastic deformation of zirconium was performed by the HPT method. Disc-shaped samples suitable for HPT deformation were cut by spark erosion from the initial Zr rod normal to the longitudinal rod axis. The diameters of samples were $8 \mathrm{~mm}$. Samples were processed by 5 revolutions at hydrostatic pressures of 2 and $4 \mathrm{GPa}$ and temperatures $300 \mathrm{~K}$ and $77 \mathrm{~K}$. The temperature of $77 \mathrm{~K}$ was achieved by placing the sample and HPT plungers in liquid nitrogen. Shear strains up to about 200 have been achieved during severe plastic deformation. Values of shear strain have been calculated by using the equation $\gamma=2 \pi n r / h$. Here, $n$ is the number of rotations, $r$ the distance from the rotation axis, and $h$ the sample thickness achieved after HPT processing. Plungers have been rotated at a speed of 0.2 rot $\min ^{-1}$. The average initial thickness of the samples was $0.77 \mathrm{~mm}$, and the thickness reduction during HPT processing did not exceed $28 \%$. Some of the samples were annealed in vacuum at $573 \mathrm{~K}$ for $3 \mathrm{~h}$ after HPT deformation.

The microstructure of the HPT samples was studied using a Philips CM200 transmission electron microscope operated at an acceleration voltage of $200 \mathrm{kV}$. For transmission electron microscopy, discs of $2.3 \mathrm{~mm}$ diameter were cut from the samples by spark erosion and mechanically ground to a thickness of about $0.15 \mathrm{~mm}$. Then the discs were electro-polished to perforation using an electrolyte consisting of $5 \%$ perchloric acid and $95 \%$ ethanol at $-20^{\circ} \mathrm{C}$.

Compression samples with the shape of rectangu- lar prisms $0.6 \times 0.8 \times 1 \mathrm{~mm}^{3}$ were cut from HPT discs by spark erosion in such way (Fig. 1) that the largest dimension of the sample was along the radial direction of the HPT disc, which also was chosen as the compression axis. The samples were cut $1-3 \mathrm{~mm}$ apart from the centre of HPT disc, which corresponds to HPT shear strains of about 50-160. Saturation of strength because of saturation of grain size (stage $\mathrm{V}$ of deformation) is achieved in HPT $\mathrm{Zr}(2 \mathrm{GPa})$ at shear strains of about 40 [12], so all compression samples cut from HPT disc had the same microstructure, and the gradient of shear strain along the samples has no influence on microstructure and mechanical properties of the samples.

Discs of coarse-grained $\mathrm{Zr}$ were cut from initially extruded rod perpendicular to the rod axis. Coarse-grained compression samples with dimensions $1.8 \times 2.0 \times 2.8 \mathrm{~mm}^{3}$ were cut from these discs similarly to the HPT samples case (Fig. 1). Such orientations of the compression axis of HPT nanostructured and coarse-grained samples yield similar initial textures for all studied structural states [13], which is important for comparison of the deformation curves.

The mechanical characteristics of HPT-nanostructured and coarse-grained $\mathrm{Zr}$ samples were studied at temperatures of $300 \mathrm{~K}, 77 \mathrm{~K}$ (in liquid nitrogen), and $4.2 \mathrm{~K}$ (in liquid helium) by recording the load-time curves for compression of the sample with relative strain rate $5 \times 10^{-4} \mathrm{~s}^{-1}$ in an MRK-3 deformation machine. The registered curves were converted into stress-plastic strain diagrams $\sigma(\varepsilon)$. The stress quantity $\sigma$ was determined as the ratio of the load and the initial cross-sectional area of a sample, and the value of plastic strain $\varepsilon$ was calculated as the compression induced change of sample length relative to its initial length.

Texture measurements of coarse-grained and HPT $\mathrm{Zr}$ were performed using a high-resolution Bruker-AXS D 8 X-Ray diffractometer in combination with a $2 \mathrm{D}$ detector, using $\mathrm{Cu} \mathrm{K} \alpha$ radiation. The beam was collimated to a spot size of $300 \mu \mathrm{m}$. The Orientation Distribution Function (ODF) has been calculated using the Arbitrary Defined Cells method [14] with LABOTEX 3.0 texture analysis software [15]. Textures were measured in that plane, which is normal to the radius of HPT disc (and initial coarse-grained disc) - with an offset of $2 \mathrm{~mm}$ from the centre of the

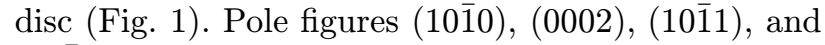
(1012) have been registered.

\section{Results and discussion}

\subsection{Microstructure of zirconium in different structural states}

Several states of the nanostructured zirconium all 

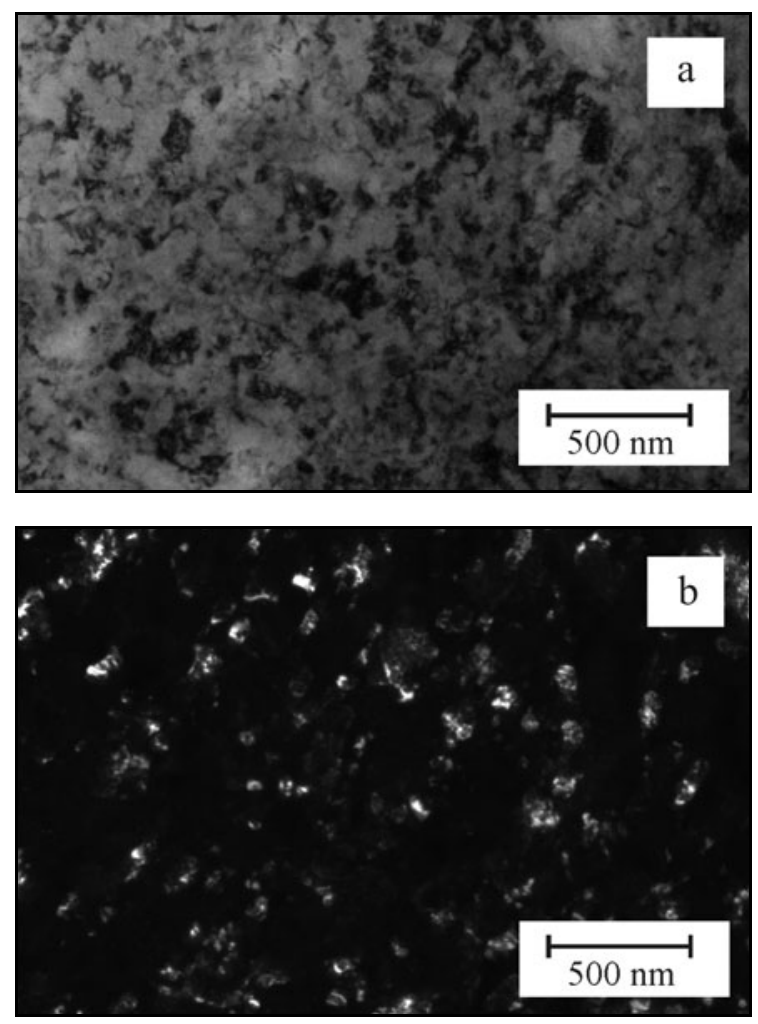

Fig. 2. Transmission electron microscopy images of Zr, processed by HPT at a temperature of $77 \mathrm{~K}$ and pressure of 2 GPa: (a) bright field; (b) dark field.

being processed by HPT to shear strains $\gamma \cong 200$ have been studied:

1. HPT Zr, processed at pressure of $2 \mathrm{GPa}$ and temperature of $300 \mathrm{~K}$, average grain size of $200 \mathrm{~nm}(\alpha$ phase);

2. HPT Zr, processed at pressure of $4 \mathrm{GPa}$ and temperature of $300 \mathrm{~K}$, average grain size of $100 \mathrm{~nm}$, with transformation of $\mathrm{Zr}$ to $\omega$ phase because of the high pressure applied during HPT (all other studied structural states of $\mathrm{Zr}$ showed $\alpha$ phase being typical of "normal" conditions);

3. HPT Zr, processed at pressure of $4 \mathrm{GPa}$ and temperature of $300 \mathrm{~K}$, followed by annealing at $573 \mathrm{~K}$ for $3 \mathrm{~h}$, average grain size of $170 \mathrm{~nm}$ ( $\alpha$ phase);

4. HPT Zr, processed at a pressure of $2 \mathrm{GPa}$ and temperature of $77 \mathrm{~K}$, average grain size of $80 \mathrm{~nm}(\alpha$ phase).

Also, coarse-grained Zr (extruded, annealed) with average grain size of $10 \mu \mathrm{m}$ was studied for comparison with the nanostructured states. A detailed description of microstructural investigations of nanostructured states 1-3 and also of coarse-grained $\mathrm{Zr}$ can be found in our previous paper [13].

In the present paper, especially state 4 of $\mathrm{Zr}$ is reported for the first time: it has been processed by $\mathrm{HPT}$ at a cryogenic temperature of $77 \mathrm{~K}$ at $2 \mathrm{GPa}$. As

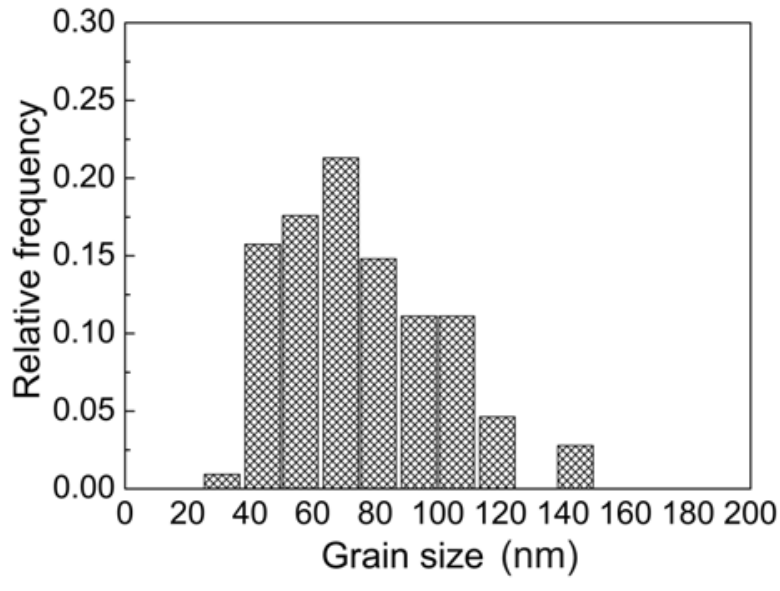

Fig. 3. Histogram of the grain size distribution - data from several images, for $\mathrm{Zr}$, processed by $\mathrm{HPT}$ at a temperature of $77 \mathrm{~K}$ and a pressure of $2 \mathrm{GPa}$.

a result, a very fine-grained and uniform microstructure has developed (Fig. 2) with average grain size of $80 \mathrm{~nm}$. A histogram of the corresponding grain size distribution is displayed in Fig. 3. It can be seen that HPT processing at cryogenic temperature of $77 \mathrm{~K}$ achieves a more efficient fragmentation of grains with much smaller final grain sizes (around $80 \mathrm{~nm}$ ) in comparison to processing at $300 \mathrm{~K}$ (around $200 \mathrm{~nm}$ ). This effect can be explained by lower dynamic recovery during processing at low temperature $[7,16]$ and also by the formation of twins occurring during fragmentation of grains at this low processing temperature [17].

Reorientation of grains after HPT deformation can be monitored by measuring the crystallographic texture of initial coarse-grained and nanostructured states (Fig. 4).

In Fig. 4, the radial direction (RD) is normal to the plane of HPT disc (or a disc of initial coarse-grained $\mathrm{Zr}$ ), the tangential direction (TD) is in the plane of HPT disc and coincides with the shear plane (see Fig. 1 for more details). Pole figures of (0002) show basal plane orientations of crystallites, whereas those of (1010) demonstrate the orientation of prismatic planes. It can be seen from Fig. 4 that initial coarse-grained Zr has a typical extrusion texture with $c$-axis of crystallites preferably oriented perpendicularly to the longitudinal axis of the initial rod (radial direction). HPT processing of $\mathrm{Zr}$ at $300 \mathrm{~K}$ and $2 \mathrm{GPa}$ leads to a considerable change in texture compared to that of the initial material: the $c$-axis of majority of crystallites gets oriented at $70^{\circ}-90^{\circ}$ to shear direction, which means that orientation of prismatic planes allows for dislocation slip. The texture after HPT at $77 \mathrm{~K}$ is quite different, indicating the activity of an additional deformation mechanism producing a considerable reorientation of grains. As it is well known [18] that twinning can be such mechanism in low- 


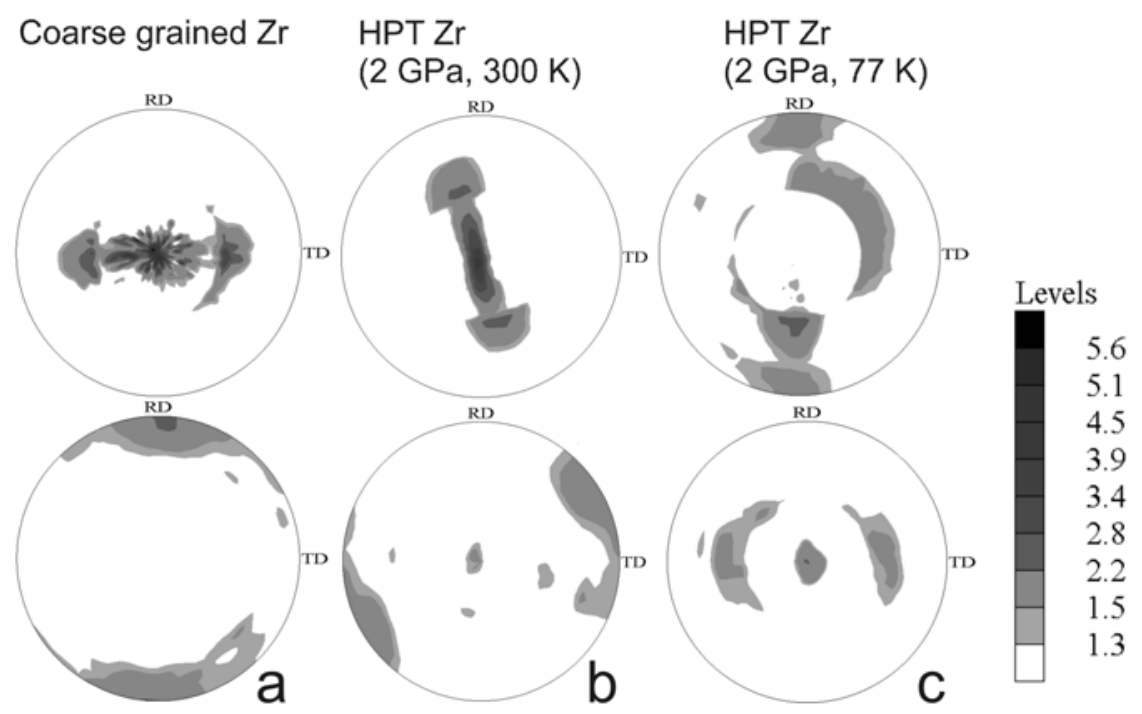

Fig. 4. (0002) and (10̄̄0) pole figures (upper and lower row, respectively) of $\mathrm{Zr}$ in (a) initial coarse-grained state; (b) nanostructured state, after HPT at $300 \mathrm{~K}$ and $2 \mathrm{GPa}$; (c) nanostructured state, after HPT at $77 \mathrm{~K}$ and $2 \mathrm{GPa}$.

-temperature deformation of $\mathrm{Zr}$, it is reasonable that twinning is the main reason for observed differences in textures of HPT at 300 and $77 \mathrm{~K}$.

\subsection{Mechanical properties}

Figure 5 shows the compressive deformation curves done at different temperatures of the initial coarsegrained $\mathrm{Zr}$, and $\mathrm{Zr}$ in several different structural states after HPT. For coarse-grained Zr, plastic deformation ceased at approx. 14-15\% plastic deformation (Fig. 5a). Samples of HPT Zr in all studied structural states were deformed until failure, which occurred by nucleation of a crack tilted approximately at $45^{\circ}$ to compression axis, and by shifting the two parts of the sample relatively to each other along the plane of the crack. This type of failure is typical of nanostructured hcp metals [19].

From Fig. 5 it is possible to discuss the plasticity of HPT Zr in the structural states studied: initial coarse-grained Zr (Fig. 5a) has good plasticity at all temperatures studied; HPT Zr (4 GPa, 300 K) (Fig. 5b) only yields about $1-2 \%$ of plastic deformation at temperatures 300 and $77 \mathrm{~K}$, and shows no plasticity at all at $4.2 \mathrm{~K}$; such small values of plastic deformation indicate that the $\omega$ phase of $\mathrm{Zr}$ observed in this material cannot produce a sufficient number of plasticity carriers. All other structural states of Zr studied which exhibit the hcp $\alpha$ phase demonstrate a better plasticity. HPT-Zr (2 GPa, $300 \mathrm{~K}$ ) (Fig. 5c) shows reasonable plasticity at $300 \mathrm{~K}$, but decreasing the test temperature leads to considerable decrease of plasticity and - as in case of HPT-Zr $(4 \mathrm{GPa}, 300 \mathrm{~K})$ at $4.2 \mathrm{~K}$ - practically no plasticity is observed.

The annealed state of HPT $\mathrm{Zr}$ (4 GPa, $300 \mathrm{~K}$ ) (Fig. 5d) shows higher plasticity (approximately $15 \%$ of plastic deformation at all temperatures studied) in comparison with as-processed HPT-Zr, but the increase of plasticity, in this case, is accompanied by a $20 \%$ decrease in strength in comparison with unannealed structural state. The alternative method of increasing the plasticity appears to be HPT deformation at a lower temperature. As can be seen from Fig. 5e, HPT at a temperature of $77 \mathrm{~K}$ and $2 \mathrm{GPa}$ leads to good plasticity at all temperatures studied, and the strength of this material is higher in comparison with HPT at $300 \mathrm{~K}$ and 2 GPa. So, HPT processing of $\mathrm{Zr}$ at cryogenic temperatures allows producing the nanostructured state with the best combination of high strength and good plasticity.

The reasons for the extended plasticity reported for the two latter cases may be explained as follows: (1) For the case of annealed HPT-Zr as compared to the as-processed state, annealing leads to a decrease of density of HPT-induced defects and thus possible sites for crack nucleation. Moreover, the annealed HPT-Zr has also more regular and low-energy grain boundaries, which can sustain higher levels of plastic deformation. (2) To understand high plasticity of HPT-Zr processed at cryogenic temperature of $77 \mathrm{~K}$, two reasons are proposed:

(i) The presence of grown-in twins in coarse-grained hcp Ti leads to an increase of plasticity in all the temperature range of 4.2-293 K [20]. HPT processing of hcp $\mathrm{Zr}$ at $77 \mathrm{~K}$ also leads to formation of deformation twins that may cause high plasticity, because the twin boundaries can serve as additional sources of dislocations [21];

(ii) The release of hydrostatic pressure after HPT deformation leads to considerable static recovery even for materials with high melting temperature as $\mathrm{Ni}$ [22]. Apparently, if finishing of HPT processing is accom- 

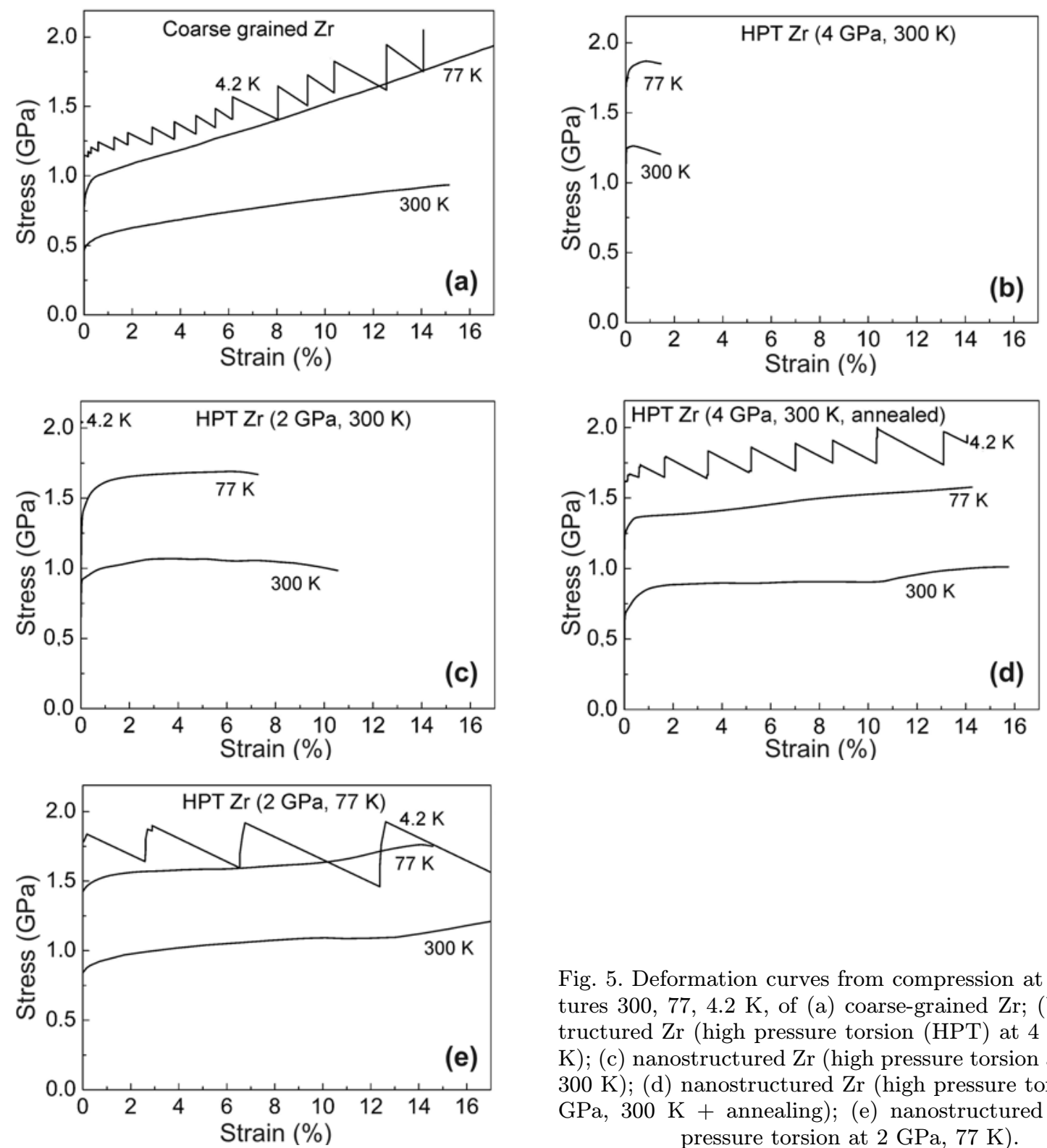

panied by a considerable temperature increase (from 77 to $300 \mathrm{~K}$ in case of cryogenic HPT deformation) the static recovery should be even stronger; the density of dislocations in grains decreases and the grain boundaries become more relaxed. The change of temperature after HPT from 77 to $300 \mathrm{~K}$ can be considered as annealing of material, and correspondingly the plasticity of this "annealed" material should be higher in comparison to HPT processing done at $300 \mathrm{~K}$.

The deformation curve of the nanostructured HPT-Zr (4 GPa, $300 \mathrm{~K}$, annealed) can be also compared (Fig. 6) with ultrafine-grained $\mathrm{Zr}$, processed by a combination of extrusion, annealing and wire drawing (see [18]). Both these materials exhibit similar average grain size of $200 \mathrm{~nm}$, but the yield stress of the HPT processed $\mathrm{Zr}$ is 1.5-2.5 times higher at the same temperatures. Such a large difference of strength in

Fig. 5. Deformation curves from compression at temperatures $300,77,4.2 \mathrm{~K}$, of (a) coarse-grained $\mathrm{Zr}$; (b) nanostructured $\mathrm{Zr}$ (high pressure torsion (HPT) at $4 \mathrm{GPa}, 300$ $\mathrm{K}$ ); (c) nanostructured $\mathrm{Zr}$ (high pressure torsion at $2 \mathrm{GPa}$, $300 \mathrm{~K}$ ); (d) nanostructured $\mathrm{Zr}$ (high pressure torsion at 4 GPa, $300 \mathrm{~K}+$ annealing); (e) nanostructured Zr (high pressure torsion at $2 \mathrm{GPa}, 77 \mathrm{~K})$.

materials with similar microstructure can be explained by the lower purity of the HPT-processed material. It is known $[6,23]$ that changes of concentration of interstitial impurities, such as oxygen, carbon, etc., may drastically affect the strength characteristics of hcp metals. The concentration of impurities of nanostructured $\mathrm{Zr}$ investigated in present work is approximately two times higher than that of the ultrafine-grained Zr [18], which apparently leads to the observed increase in strength in both coarse-grained (Fig. 6a,b) and nanograined (Fig. 6c,d) Zr.

The increase of strain hardening in coarse-grained and ultrafine-grained Zr of higher purity (Fig. 6b,d) after approximately 4-6\% of plastic deformation was explained in [18] by the effect of twinning: new twin boundaries act as additional barriers to dislocation motion and the active twin system (in that 

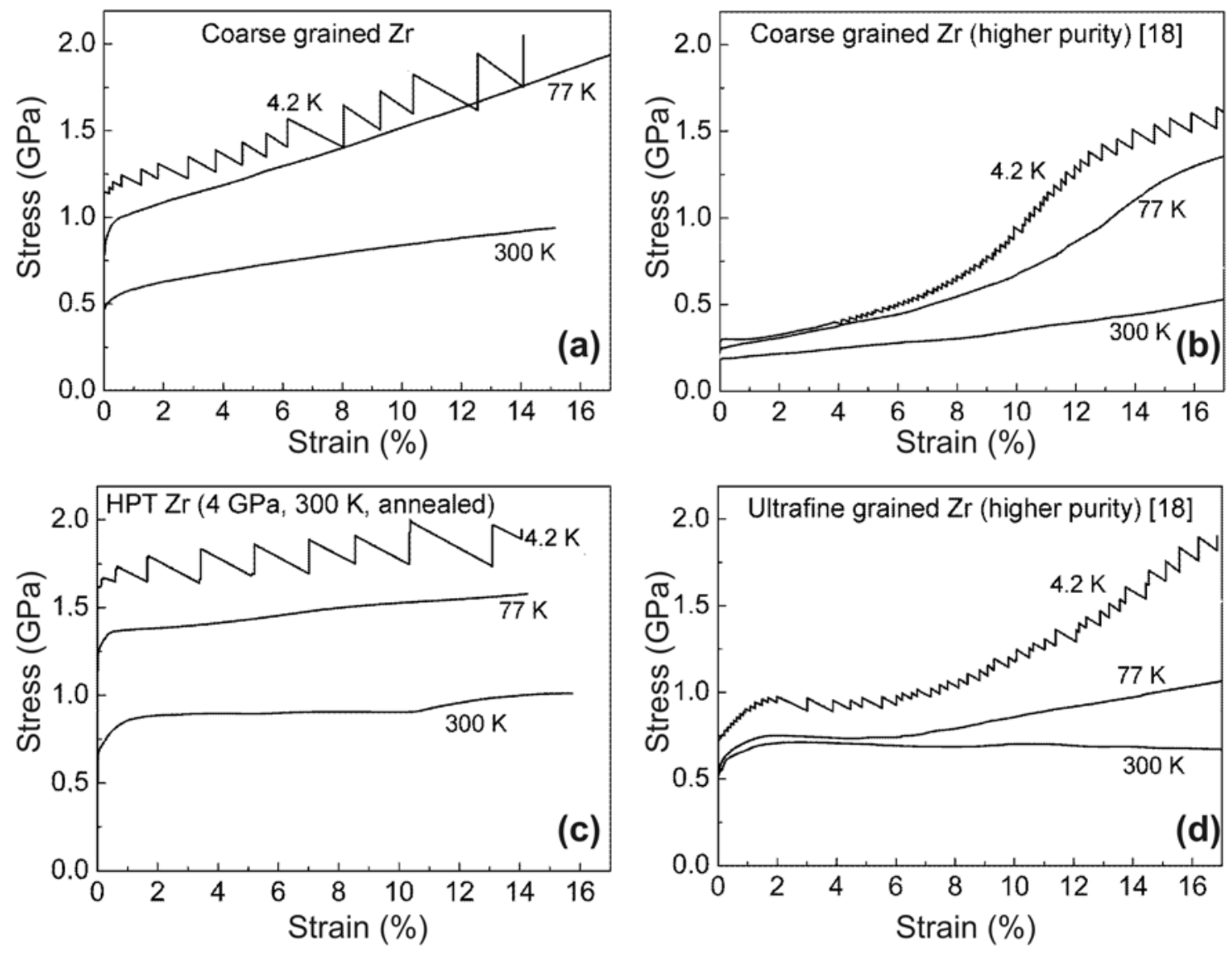

Fig. 6. Comparison of deformation curves done by compression at temperatures 300, 77, and 4.2 K, in Zr with different purities: (a) low purity Zr, coarse-grained; (b) high purity Zr, coarse-grained [18]; (c) low purity nanostructured Zr (high pressure torsion (HPT) at $4 \mathrm{GPa}, 300 \mathrm{~K}+$ annealing); and (d) high purity ultrafine grained $\mathrm{Zr}$ (annealed) [18].

case $\{10 \overline{1} 2\}$ ) reorients grains to a position that is not favourable for gliding of prismatic dislocations, thus leading to additional and considerable strain hardening. Lower purity $\mathrm{Zr}$ studied in this work in the coarse-grained and nanostructured state (Fig. 6a,c), does not show such considerable increase of strain hardening, indicating only lower activity of twinning. Moreover, it should be mentioned that with initial textures (Fig. 4a,b), where a lot of grains are oriented by $c$-axis in the direction of compression, the twinning should not reorient grains to a position where prismatic dislocation is not active $[1,3,18]$. Thus, strain hardening will not further increase.

Serrated plastic flow is observed at the temperature $4.2 \mathrm{~K}$ for all structural states studied, which show some plasticity at this temperature. At this low temperature, the effect is typical of many metals and alloys including coarse-grained Zr, and can be explained by localization of plastic deformation and collective and interrelated motion of plasticity carriers [24, 18]. The amplitude of serrations is approximately the same in coarse-grained and nanostructured Zr (Fig. 6a,c). The depth of serrations is considerably larger in lower purity Zr in both coarse-grained and nanostructured

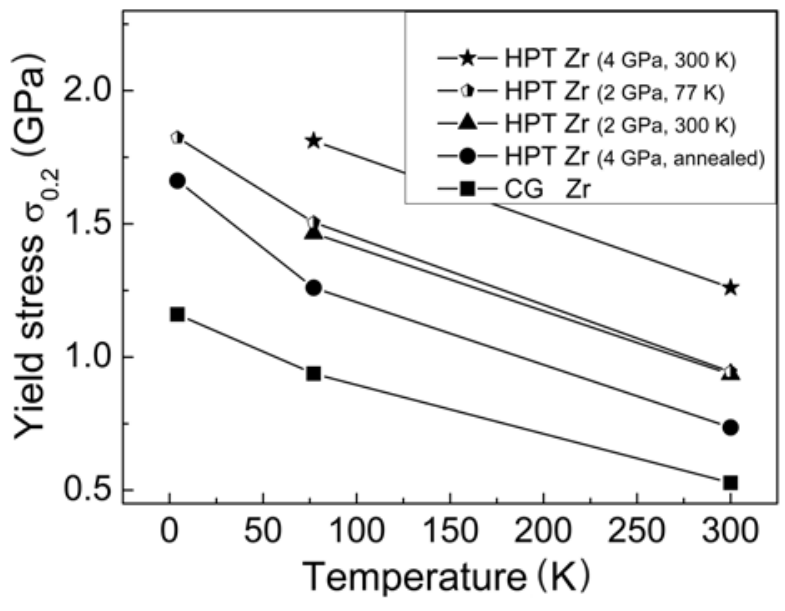

Fig. 7. Dependences of yield stress on compression temperature for initial coarse-grained $\mathrm{Zr}$ and nanostructured $\mathrm{Zr}$, processed by high-pressure torsion (HPT) at different temperatures and pressures as indicated in the insert.

states (Fig. 5a,c,f) in comparison to the same states with higher purity Zr (Fig. 6b,d).

The temperature dependences of the yield stress 
for the studied structural states are shown in Fig. 7.

At a temperature of $300 \mathrm{~K}$ the microhardness for most of these states was measured in our previous paper [13], and comparison of these values with those of compression yield stress of the present paper shows that the empirical relation $H_{\mathrm{V}}=3 \sigma_{0.2}$ is fulfilled rather well for all states investigated. In all studied structural states an increase of $\sigma_{0.2}$ values with decreasing compression temperature $T$ was registered, which is typical of thermally activated plasticity. It can be seen from Fig. 7 that yield stress of the nanostructured $\mathrm{Zr}$ (processed by HPT at $2 \mathrm{GPa}$ ) is approximately 1.7 times higher in comparison with coarsegrained $\mathrm{Zr}$ at all studied temperatures. This increase of stress is mainly due to the difference in grain size spanning $10 \mu \mathrm{m}-200 \mathrm{~nm}$. HPT at temperature of $77 \mathrm{~K}$ leads to smaller grain sizes and correspondingly to higher values of yield stress in comparison with HPT at $300 \mathrm{~K}$. HPT-Zr (processed at $4 \mathrm{GPa}$ and $300 \mathrm{~K}$ ) gives an even higher yield stress (2-2.4 times in comparison with coarse-grained Zr), but this additional increase of strength cannot be explained only by the difference in grain size, which actually is $100 \mathrm{~nm}$ and thus only twice smaller in comparison with HPT (2 GPa, $300 \mathrm{~K}$ ). The main reason of this high strength (and low plasticity) is apparently the presence of $\omega$ phase, which is unique for the status achieved by HPT at $4 \mathrm{GPa}$ and exhibits a quite different mechanisms of plastic deformation in comparison with all other states showing the $\alpha$ phase. Annealing of the HPT-nanostructured Zr leads to an approximately $20 \%$ decrease in yield stress at all temperatures studied again due to a decrease of HPT-induced defect density within the grains.

\section{Summary}

The results of this work can be summarised as follows:

- HPT at temperature of $300 \mathrm{~K}$ allows to produce high-strength structural states of $\mathrm{Zr}$ with average grain sizes 100-200 nm, whose yield stress reaches $1.3 \mathrm{GPa}$ at $300 \mathrm{~K}$, and $2 \mathrm{GPa}$ at $4.2 \mathrm{~K}$ exceeding the strength of coarse-grained $\mathrm{Zr}$ (grain size $10 \mu \mathrm{m}$ ) by nearly 2.5 times. The maximum strength is reached after HPT at $4 \mathrm{GPa}$ when phase transition to $\omega$ phase occurs;

- plasticity of nanostructured $\alpha$-Zr is much higher in comparison to that of $\omega-\mathrm{Zr}$, and annealed states of nanostructured $\mathrm{Zr}$ have higher plasticity in comparison with unannealed states;

- the texture of $\mathrm{Zr}$ after HPT at $77 \mathrm{~K}$ is rather different to that after HPT performed at $300 \mathrm{~K}$. It indicates activity of an additional deformation mechanism, i.e. twinning;

- HPT deformation at cryogenic temperature of $77 \mathrm{~K}$ allows to achieve the smallest average grain sizes
$(80 \mathrm{~nm})$ due to lower dynamic recovery and due to participation of twinning in fragmentation of grains during low-temperature processing;

- the structural state with the best combination of high strength and good plasticity was achieved by HPT at $77 \mathrm{~K}$. The high plasticity values of this state observed at all deformation temperatures studied can be explained by the presence of HPT induced twin boundaries, and of low energy grain boundaries formed during static recovery in course of HPT unloading and/or temperature increase from 77 to $300 \mathrm{~K}$.

\section{Acknowledgements}

The authors are grateful for financial support within the Scientific-Technical Cooperation Project AustriaUkraine UA 16/2011 (M/185-2012). The research of this work was partially funded by the Austrian Science Fund FWF within projects S 10403 and T512-N20.

\section{References}

[1] Kaschner, G. C., Tome, C., Beyerlein, I., Vogel, S., Brown, D., McCabe, R.: Acta Mater., 54, 2006, p. 2887. doi:10.1016/j.actamat.2006.02.036

[2] Reed-Hill, R. E.: In: Deformation Twinning. Eds.: Reed-Hill, R. E., Hirth, J. P., Rogers, H. C. Warrendale, TMS 1964, p. 295.

[3] McCabe, R. J., Proust, G., Cerreta, E. K., Misra, A.: Int. J. Plast., 25, 2009, p. 454. doi:10.1016/j.ijplas.2008.03.001

[4] Morrow, B. M., McCabe, R. J., Cerreta, E. K., Tomé, C. N.: Mater. Sci. Eng., A574, 2013, p. 157. doi:10.1016/j.msea.2013.02.043

[5] Rangaswamy, P., Bourke, M. A. M., Brown, D. W., Kaschner, G. C., Rogge, R. B., Stout, M. G., Tome, C. N.: Metall. Mater. Trans., A33, 2002, p. 757. doi:10.1007/s11661-002-0142-1

[6] Kaschner, G. C., Gray III, G. T.: Metall. Mater. Trans., A31, 2000, p. 1997. doi:10.1007/s11661-000-0227-7

[7] Zehetbauer, M. J., Zhu, Y. T.: Bulk Nanostructured Materials. Weinheim, VCH-Wiley 2009. doi:10.1002/9783527626892.indsub

[8] Estrin, Y., Vinogradov, A.: Acta Mater., 61, 2013, p. 782. doi:10.1016/j.actamat.2012.10.038

[9] Valiev, R. Z., Estrin, Yu., Horita, Z., Langdon, T. G., Zehetbauer, M. J., Zhu, Y. T.: JOM, 58, 2006, p. 33. doi:10.1007/s11837-006-0213-7

[10] Srinivasarao, B., Zhilyaev, A. P., Perez-Prado, M. T.: Scripta Mater., 65, 2011, p. 241. doi:10.1016/j.scriptamat.2011.04.017

[11] Shen, X., Yu, P. F., Jing, Q., Yao, Y., Gu, L., Wang, Y. G., Duan, X. F., Yu, R. C., Liu, R. P.: Scripta Mater., 67, 2012, p. 653. doi:10.1016/j.scriptamat.2012.07.017

[12] Edalati, K., Horita, Z., Yagi, S., Matsubara, E.: Mater. Sci. Eng. A, 523, 2009, p. 277. doi:10.1016/j.msea.2009.07.029 
[13] Podolskiy, A. V., Bonarski, B., Setman, D., Mangler, C., Schafler, E., Tabachnikova, E. D., Zehetbauer, M. J.: Mat. Sci. Forum, 667-669, 2011, p. 433. doi:10.4028/www.scientific.net/MSF.667-669.433

[14] Van Houtte, P.: Texture Microstruct., 13, 1991, p. 199. doi:10.1155/TSM.13.199

[15] Pawlik, K., Ozga, P.: LaboTex: The Texture Analysis Software. Göttinger Arbeiten zur Geologie und Paläontologie SB4. Göttingen, 1999.

[16] Wang, Y. M., Ma, E.: Acta Mater., 52, 2004, p. 1699. doi:10.1016/j.actamat.2003.12.022

[17] Moskalenko, V. A., Smirnov, A. R., Moskalenko, A. V.: Low Temp. Phys., 35, 2009, p. 1160. doi:10.1063/1.3266928

[18] Podolskiy, A. V., Smirnov, S. N., Tabachnikova, E. D., Bengus, V. Z., Velikodny, A. N., Tikhonovsky, M. A., Bonarski, B., Mangler, C., Zehetbauer, M. J.: Low Temp. Phys., 37, 2011, p. 609. doi:10.1063/1.3645014
[19] Miškuf, J., Csach, K., Juríková, A., Ocelík, V., De Hosson, J. Th. M., Bengus, V. Z., Tabachnikova, E. D., Podolskiy, A. V., Valiev, R. Z.: Kovove Mater., 47, 2009, p. 295.

[20] Smirnov, A. R., Moskalenko, V. A.: Mat. Sci. Eng., A327, 2002, p. 138. doi:10.1016/S0921-5093(01)01648-3

[21] Wu, Z. X., Zhang, Y. W., Srolovitz, D. J.: Acta Mater., 59, 2011, p. 6890. doi:10.1016/j.actamat.2011.07.038

[22] Schafler, E.: Scripta Mater., 64, 2011, p. 130. doi:10.1016/j.scriptamat.2010.09.026

[23] Tabachnikova, E. D., Bengus, V. Z., Podolskiy, A. V., Smirnov, S. N., Gunderov, D. V., Valiev, R. Z.: Mater. Sci. Forum, 503-504, 2006, p. 633. doi:10.4028/www.scientific.net/MSF.503-504.633

[24] Pustovalov, V. V.: Low Temp. Phys., 34, 2008, p. 683. doi:10.1063/1.2973710 